\title{
Excessive Autophagy Activation and Increased Apoptosis Are Associated with Palmitic Acid-Induced Cardiomyocyte Insulin Resistance
}

\author{
Shanxin Li, ${ }^{1}$ Hui Li, ${ }^{1}$ Di Yang, ${ }^{1}$ Xiuyan Yu, ${ }^{1}$ David M. Irwin, ${ }^{2}$ Gang Niu, ${ }^{3}$ and Huanran Tan ${ }^{1}$ \\ ${ }^{1}$ Department of Pharmacology, School of Basic Medical Sciences, Health Science Center, Peking University, Beijing 100191, China \\ ${ }^{2}$ Department of Laboratory Medicine and Pathobiology, University of Toronto, Toronto, ON, Canada M5S 1A8 \\ ${ }^{3}$ Beijing N\&N Genetech Company, Beijing 100082, China
}

Correspondence should be addressed to David M. Irwin; david.irwin@utoronto.ca, Gang Niu; nngene@sohu.com, and Huanran Tan; tanlab@bjmu.edu.cn

Received 7 June 2017; Revised 26 August 2017; Accepted 12 September 2017; Published 26 November 2017

Academic Editor: Marta L. Hribal

Copyright @ 2017 Shanxin Li et al. This is an open access article distributed under the Creative Commons Attribution License, which permits unrestricted use, distribution, and reproduction in any medium, provided the original work is properly cited.

\begin{abstract}
Diabetic cardiomyopathy (DCM) remains the major cause of death associated with diabetes. Researchers have demonstrated the importance of impaired cardiac insulin signaling in this process. Insulin resistance (IR) is an important predictor of DCM. Previous studies examining the dynamic changes in autophagy during IR have yielded inconsistent results. This study aimed to investigate the dynamic changes in autophagy and apoptosis in the rat H9c2 cardiomyocyte IR model. H9c2 cells were treated with $500 \mu \mathrm{M}$ palmitic acid (PA) for 24 hours, resulting in the induction of IR. To examine autophagy, monodansylcadaverine staining, GFP-LC3 puncta confocal observation, and Western blot analysis of LC3I-to-LC3II conversion were used. Results of these studies showed that autophagic acid vesicles increased in numbers during the first 24 hours and then decreased by 36 hours after PA treatment. Western blot analysis showed that treatment of H9c2 cells with $500 \mu \mathrm{M}$ PA for 24 hours decreased the expression of Atg12-Atg5, Atg16L1, Atg3, and PI3Kp85. Annexin V/PI flow cytometry revealed that PA exposure for 24 hours increased the rate of apoptosis. Together, this study demonstrates that PA induces IR in H9c2 cells and that this process is accompanied by excessive activation of autophagy and increases in apoptosis.
\end{abstract}

\section{Introduction}

It was recently estimated that 415 million people suffered from diabetes globally in 2015 [1]. Diabetic cardiomyopathy (DCM) is a major complication that accounts for more than half of the diabetes-related morbidity and mortality cases [2]. DCM has been defined as ventricular dysfunctions that occur in diabetic patients independent of recognized cause, such as coronary artery disease or hypertension [3]. Insulin resistance, which is defined by a decrease in glucose disposal in response to insulin by target tissues [4], is an important risk factor for cardiovascular morbidity [4, 5]. However, the molecular mechanisms of insulin resistance in the pathogenesis of DCM remain to be elucidated.
Elevated free fatty acid (FFA) plasma levels contribute to obesity-associated insulin resistance. Previous research demonstrated that increased lipid levels in the heart result in deficiencies of myocardium contraction and left ventricular dysfunction [6]. Saturated long-chain FFA such as palmitic acid (PA) and stearic acid was potent inducers of these dysfunctional effects [7]. PA is the main component of dietary saturated fat, accounting for nearly $20 \%$ of the total serum FFA. High levels of PA are widely used to study FFA-induced insulin resistance [8]. In vitro studies indicated that insulin resistance was induced in a human endothelial cell line by 250 to $1000 \mu \mathrm{M}$ PA [9] and in primary rat ventricular myocytes by $500 \mu \mathrm{M}$ PA for 24 hours [10]. In vivo experiments showed that high levels of palmitic acid 
lead to insulin resistance due to changes in the level of phosphorylation of the insulin receptor and insulin receptor substrate- 1 in rats [4].

Autophagy is a cellular protein degradation system that enables cells to recycle cytoplasmic components by degradation in the lysosomes [11]. While there have been a few studies examining the relationship between autophagy and insulin resistance, their conclusions have been inconsistent. Yang et al. [12] observed a downregulation of autophagy, particularly in Atg7 expression levels, in both genetic and dietary models of obesity. They found that the suppression of Atg7, both in vitro and in vivo, resulted in defective insulin signaling. In contrast, Ost et al. [13] demonstrated attenuated mTOR signaling and enhanced autophagy in adipocytes from obese patients with type 2 diabetes. Rapamycin (RAP) induces autophagy by inhibiting mammalian target of rapamycin complex-1 (MTORC1) [14] and is routinely applied in the study of autophagy regulation; thus, we used RAP as a positive control for autophagy induction in our study $[15,16]$.

We hypothesize that basal levels of autophagy are necessary for maintaining cellular insulin signaling, yet excessive autophagy may lead to impaired insulin signaling. The aim of the present study was to explore the role of autophagy in insulin resistance in rat cardiomyocyte model induced by PA to elucidate the molecular mechanisms leading to DCM and help find candidate drug targets to treat DCM.

\section{Materials and Methods}

2.1. Materials and Reagents. Dulbecco's Modified Eagle Medium (DMEM) culture media were obtained from Life Technologies (USA). Autophagy inducer rapamycin (RAP) and $4^{\prime}, 6^{\prime}$-diamidino-2-phenylindole (DAPI) were purchased from Solarbio (Beijing, China). Autophagy inhibitor hydroxychloroquine sulfate (HCQ) was obtained from Tokyo Chemical Industry (Japan). Monodansylcadaverine (MDC) was purchased from Sigma-Aldrich LLC (USA).

2.2. Cell Culture. Immortalized rat cardiac myoblastic cells H9c2 were obtained from the Shanghai Institute of Biochemistry and Cell Biology (China). Cells were cultured in high-glucose DMEM medium supplemented with $100 \mathrm{U} / \mathrm{ml}$ penicillin, $100 \mu \mathrm{g} / \mathrm{ml}$ streptomycin, and $10 \%$ heat-inactivated FBS (Thermo Fisher Scientific, USA) and maintained at $37^{\circ} \mathrm{C}$ and $5 \% \mathrm{CO}_{2}$. One day before experiments, cells were incubated in culture medium supplemented with 1\% FBS to allow the cells to differentiate into cardiomyocytes [17].

2.3. PA Treatment. PA was administered to cells by conjugating it with bovine serum albumin (BSA) as described by Chavez et al. [18]. Briefly, PA was completely dissolved in $100 \%$ ethanol and diluted $1: 100$ in 1\% FBS-DMEM containing $2 \%(w / v)$ bovine serum albumin. The control treatment was prepared by adding the same amount of ethanol to BSA-DMEM solution. All solutions were filtered, aliquoted, and stored at $-20^{\circ} \mathrm{C}$ prior to use.

2.4. Measurement of Glucose Consumption. The consumption of glucose was measured as previously described [17, 19]. $\mathrm{H} 9 \mathrm{c} 2$ cells were seeded into 96-well culture plates (5000 cells/well) in $100 \mu \mathrm{l}$ medium for $24 \mathrm{~h}$. The medium was then replaced with media with 0,250 , or $500 \mu \mathrm{M}$ PA with or without $100 \mathrm{nM}$ RAP, and cells were cultured for another 12 or $24 \mathrm{~h}$. Insulin (100 nM) was then added to each well for the last 30 minutes. Glucose was measured from $8 \mu \mathrm{l}$ of media removed at 12 and $24 \mathrm{~h}$ of culture. The concentration of glucose in the cell media was measured with blood glucose test paper (Roche, Switzerland), with glucose production calculated after subtracting the glucose concentration found in media from DMEM culture medium wells without cells.

2.5. Western Blot Analysis. Total protein was extracted using a lysis buffer containing $50 \mathrm{mM}$ Tris- $\mathrm{HCl}$ (pH 8.0), $150 \mathrm{mM}$ $\mathrm{NaCl}, 0.02 \% \mathrm{NaN}_{3}, 0.1 \%$ SDS, $1 \mathrm{mM}$ EDTA, $1 \%$ Triton X100 , and $100 \mathrm{mg} / \mathrm{ml}$ PMSF. For each sample, $50 \mu \mathrm{g}$ of protein was separated by SDS-PAGE (with different concentrations appropriate for the molecular weight of the targeted proteins) at $80 \mathrm{~V}$ for $0.5 \mathrm{~h}$ and $120 \mathrm{~V}$ for $1 \mathrm{~h}$ using the Mini-PROTEAN 3 electrophoresis cell system (Bio-Rad, USA). Proteins were then transferred to a PVDF membrane (Bio-Rad, USA) by the semidry blotting method with Dunn carbonate transfer buffer consisting of $\mathrm{NaHCO}_{3}(10 \mathrm{mM}), \mathrm{Na}_{2} \mathrm{CO}_{3}(3 \mathrm{mM})$, and $20 \%$ methanol. Membranes were then treated with $5 \%$ nonfat milk powder in 1XTBST buffer for $1 \mathrm{~h}$ to block nonspecific binding and then incubated overnight at $4^{\circ} \mathrm{C}$ with primary antibodies. Antibodies were rabbit anti-IR- $\beta$, IRS2, LC3I and II, Atg3, Atg12, Atg16L1, Bcl2, PI3Kp85 (1:500, CST, USA), and mouse anti-GAPDH (1:1000, Abcam, USA). Antibody binding was detected using goat antirabbit or goat anti-mouse secondary antibodies (ZSGB Bio, China), which were added for $1 \mathrm{~h}$, washed 3 times, and then visualized by luminal chemiluminescence ChemiDoc XRS (Bio-Rad, USA). Band intensities were semiquantitatively analyzed by quantity-one software.

2.6. Detection of Autophagic Vesicles by Monodansylcadave rine Staining. Monodansylcadaverine (MDC), a fluorescent compound, was used as a tracer of autophagic vacuoles [20]. H9c2 cells were incubated with $50 \mu \mathrm{M}$ MDC for $30 \mathrm{~min}$ at $37^{\circ} \mathrm{C}$, according to preview literature's method [21]. Cells were then washed twice with PBS and fixed with $4 \%$ paraformaldehyde for 15 minutes before autophagosomes being observed with a confocal microscope (excitation spectrum. $405 \mathrm{~nm}$ ), (Leica TCS SP8, Germany). Data analysis was performed using Image-Pro Plus 6.0 (Media Cybernetics, USA), and the MDC positive area was calculated for each visual field.

2.7. Detection of Autophagy Flow by GFP-LC3. Autophagosomes were labeled with GFP to detect their movement. $\mathrm{H} 9 \mathrm{c} 2$ cells were transfected with a lentivirus plasmid vector containing GFP-LC3 (a gift from Qi-hua He, Center of medical and health analysis, Peking University) that targets autophagosomes. Transfected cells were seeded onto confocal culture dishes and treated with $500 \mu \mathrm{M}$ PA, with or without $100 \mathrm{nM}$ RAP for $24 \mathrm{~h}$ and with or without $50 \mu \mathrm{M}$ HCQ. HCQ was added for only the last 2 hours. Cells were then fixed with $4 \%$ paraformaldehyde and washed 3 times with PBS. Fixed cells were stained with DAPI for 15 minutes, 
washed 3 times with PBS, and observed with a confocal microscope (GFP excitation spectrum: $488 \mathrm{~nm}$; DAPI excitation spectrum: $405 \mathrm{~nm}$ ) (Leica TCS SP8, Germany). To assay autophagic flow, "LC3 net flux" was calculated after subtraction of the amount of LC3II in the absence of HCQ from the amount of LC3II in the presence of HCQ for each condition [22]. Data analysis was performed using Image-Pro Plus 6.0 (Media Cybernetics, USA) and calculated for GFP-LC3 area per cell.

2.8. RNA Extraction and Real-Time PCR. Total mRNA was extracted from H9c2 cells using TRIzol reagent (Invitrogen, USA). After the concentration of the purified mRNA was verified, reverse transcription was conducted using RevertAid first Strand cDNA Synthesis Kit (Thermo Scientific, USA) according to the manufacturer's instructions. Expression of target genes was measured by semiquantitative RT-PCR using BrilliantII SYBR Green QPCR Master Mix (Agilent, USA) and gene-specific primers following the manufacturer's protocol. PCR reaction conditions were as follows: initial denaturation at $95^{\circ} \mathrm{C}$ for $10 \mathrm{~min}$ and then 40 cycles of denaturation at $95^{\circ} \mathrm{C}$ for $30 \mathrm{~s}$ and annealing/extension at $60^{\circ} \mathrm{C}$ for $30 \mathrm{~s}, 72^{\circ} \mathrm{C}$ for $30 \mathrm{~s}$. Cycle number at threshold (Ct value) was used to calculate the relative amount of the mRNA molecules and is presented as fold-change compared to $\beta$-actin, calculated using the $2^{\triangle \Delta \mathrm{Ct}}$ method [23]. Genespecific primer sequences used for RT-PCR were as follows:

Beclin1 F: 5'-AGATGCGCTATGCCCAGATG-3', R: 5' AATTGTCCGCTGTGCCAGAT- $3^{\prime}$;

mTOR F: $5^{\prime}$-CACCCATCCAACCTGATGCT-3' ${ }^{\prime}$, R: $5^{\prime}$-T CGAGACCGGTAACCTCCAT-3';

$\beta$-actin F: $5^{\prime}$-TACAACCTTCTTGCAGCTCCT-3', R: $5^{\prime}$ TGACCCATACCCACCATCAC- $3^{\prime}$.

2.9. Cell Viability. Cell viability was examined using the MTS assay with CellTiter $96^{\circledR}$ AQueous One Solution (Promega Biotech, USA) according to the manufacturer's instructions. Briefly, H9c2 cells were seeded into 96-well culture plates (5000 cells/well) with $100 \mu \mathrm{l}$ medium and incubated overnight to allow the cells to adhere. Cells were then treated with PA $(0,250$, and $500 \mu \mathrm{M})$ with or without nM RAP for $24 \mathrm{~h}$. For the last 4 hours of culture, $20 \mu \mathrm{l}$ of MTS solution was added to each well. Absorbance was measured at $490 \mathrm{~nm}$ using an iMarK microplate reader (Bio-Rad, USA).

2.10. Apoptosis Determination. Cellular apoptosis was determined using the StarGlow Annexin V-FITC Apoptosis Detection Kit (Genestar, China). Briefly, $1 \times 10^{6}$ cells from different treatments were rinsed with PBS and suspended with $100 \mu \mathrm{l}$ of binding buffer. Subsequently, $5 \mu \mathrm{l}$ Annexin V-FITC was added and incubated for 5 min under dark conditions, and $10 \mu \mathrm{l}$ PI was added before flow cytometry (BD Biosciences, USA).

2.11. Statistical Analysis. Data are presented as mean \pm standard error of mean (SEM) from three independent experiments. Statistical differences were assessed using one-way ANOVA. First, we checked whether the variances of the data were homogeneous. If variances were homogeneous, then the
LSD statistics were applied as the post hoc test, if not, then the Tamhane statistics was employed. $P$ values less than 0.05 were considered to be significant.

\section{Results}

3.1. Insulin Resistance in H9c2 Cells Induced by $500 \mu M$ PA Treatment for $24 \mathrm{~h}$. To induce insulin resistance model, $\mathrm{H} 9 \mathrm{c} 2$ cells were treated with $500 \mu \mathrm{M}$ PA with or without RAP for 12 and 24 hours [10], and glucose consumption was measured. No changes in glucose consumption were found among groups after 12 hours (Figure 1(a), $P>0.05$ ). Glucose consumptions of the $500 \mu \mathrm{M}$ PA and the $500 \mu \mathrm{M}$ $\mathrm{PA}+\mathrm{RAP}$ groups were less than the controls at $24 \mathrm{~h}$ (Figure 1(a), $P<0.05$ ), with the glucose consumption of the $500 \mu \mathrm{M}$ PA + RAP group being less than that of the RAP group (Figure $1(\mathrm{a}), P<0.05)$. H9c2 cells treated with lower PA concentrations $(250 \mu \mathrm{M})$ for 24 hours did not show any decrease in glucose consumption compared to the control cells (data not shown).

Protein markers for insulin resistance were examined after $24 \mathrm{~h}$ of treatment groups. Expression of IR- $\beta$ was inhibited in cells treated with $500 \mu \mathrm{M}$ PA compared with the control group (Figures 1(b) and 1(c), $P<0.05$ ), with the levels of IR- $\beta$ in the $500 \mu \mathrm{M}$ PA + RAP group significantly lower than those in the RAP and control groups (Figures 1(b) and 1(c), $P<0.05)$. Similar changes were seen for IRS2 (Figures $1(\mathrm{c})$ and $1(\mathrm{~d}), P<0.05)$. Together, these data indicated that $\mathrm{H} 9 \mathrm{c} 2$ cells acquired IR after exposure to $500 \mu \mathrm{M}$ PA for $24 \mathrm{~h}$.

3.2. PA-Augmented Activation of Autophagy. The role of autophagy during insulin resistance has been controversial $[13,24,25]$; thus, we employed multiple techniques to demonstrate that PA induces dysfunctional autophagy. As autophagy is a dynamic process, we applied MDC, which accumulates in acidic vesicles, for the detection of autophagosome formation. The size of the MDC-positive particle area in cells of the $500 \mu \mathrm{M}$ PA group was increased at $24 \mathrm{~h}$ compared to $12 \mathrm{~h}$ and then decreased at $36 \mathrm{~h}$ (Figures 2(a) and $2(\mathrm{~d}), P<0.05)$. A similar trend was seen for the RAP and $500 \mu \mathrm{M}$ PA + RAP groups (Figures 2(a), 2(c), and 2(e), $P<0.05)$. However, the MDC-positive particle area did not change in the control groups (Figures 2(a) and 2(b), $P>0.05)$. Based on these findings, we hypothesized that PA enhanced autophagy flow for the first 24 hours and then decreased by 36 hours, a pattern similar to that seen with rapamycin.

We then wondered whether the increase in the number of autophagosomes was due to enhanced autophagic activity or blockage of autophagosome fusion with lysosomes. To study this, we used assays with GFP-LC3. GFP-LC3 lentivirus was employed to transfect H9c2 cells, generating cells that stably express GFP-LC3. The lysosomal inhibitor HCQ $(50 \mu \mathrm{M})$ was used to block LC3II fusion with lysosomes [22]. As illustrated in Figures 3(a) and 3(b), $500 \mu \mathrm{M}$ PA or RAP increased GFP-LC3 puncta per cell, and HCQ treatment in combination with PA or RAP yielded a significantly increased GFP-LC3 puncta (Figures 3(a) and 3(b), $P<0.05$ ). Based 


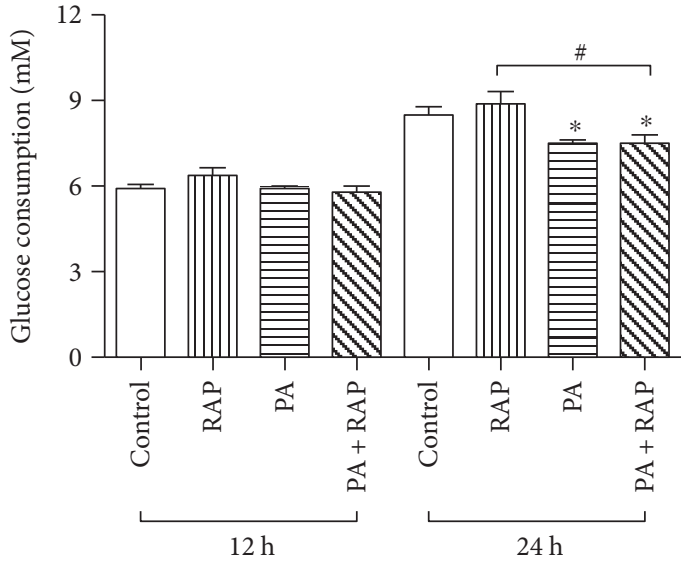

(a)

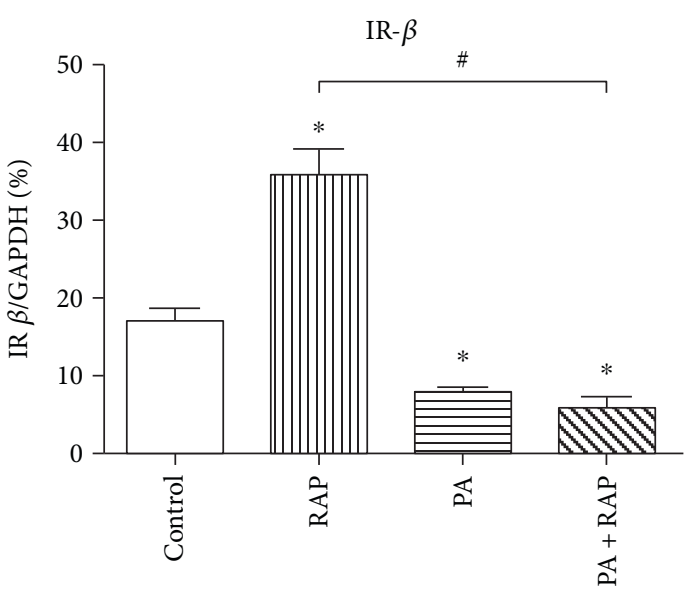

(c)

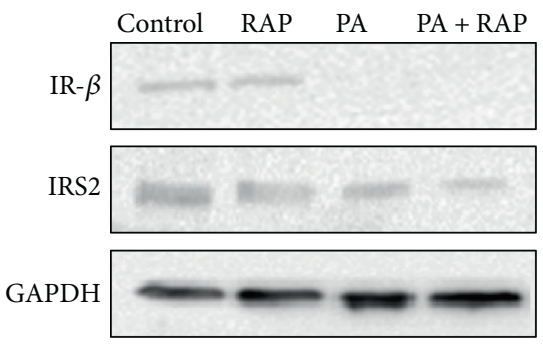

(b)

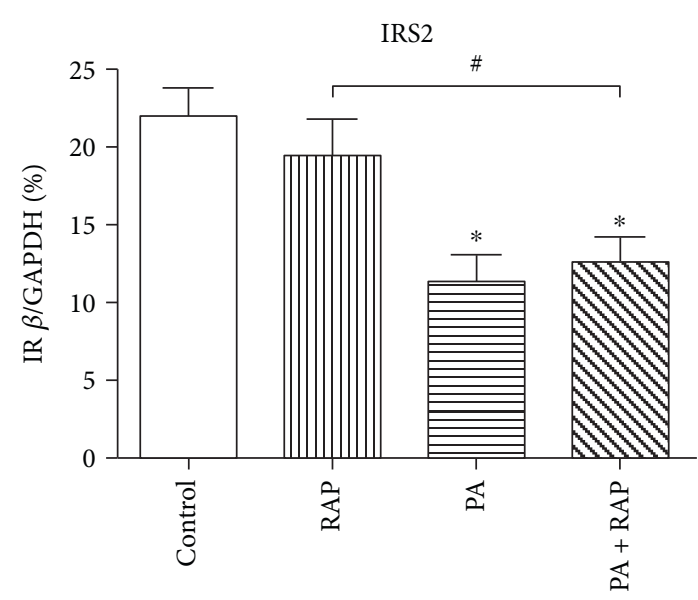

(d)

FIGURE 1: Insulin resistance in H9c2 cells was induced by $500 \mu \mathrm{M}$ PA treatment for $24 \mathrm{~h}$. (a) H9c2 were treated with solvent (control), $100 \mathrm{nM}$ RAP (RAP), $500 \mu \mathrm{M}$ PA (PA), $500 \mu \mathrm{M}$ PA $+100 \mathrm{nM}$ RAP (PA + RAP), and cultured for $12 \mathrm{~h}$ and $24 \mathrm{~h}$. Cells were incubated by adding $100 \mathrm{nM}$ insulin for the last 30 minutes. Glucose consumptions were measured. H9c2 cells were treated with drugs for $24 \mathrm{~h}$ and $100 \mathrm{nM}$ insulin was then added for the last 10 minutes. (b) Western blot analysis of IR- $\beta$ and IRS2 compared with GAPDH. (c, d) Quantification of the results from (b) $(n=3) .{ }^{*} P<0.05$ compared with the controls of the same time period. ${ }^{\#} P<0.05$ compared with RAP groups of the same time period.

on these results, we speculated that increased number of autophagosomes seen with PA exposure was mostly attributed to excessive activation of autophagic initiation, rather than the blockage of fusion of autophagosomes with lysosomes.

To measure the amount of fusion of autophagosomes (represented by LC3 puncta) with lysosomes, we defined the concept "LC3 net flux," which is calculated by subtracting the average amount of GFP-LC3 in the absence of HCQ from the amount of GFP-LC3 in the presence of HCQ for each condition [22]. Our results showed that LC3 net flux in H9c2 cells was enhanced upon exposure to $500 \mu \mathrm{M}$ PA with or without RAP for 24 hours compared to the control group (Figures 3(a) and 3(c), $P<0.05$ ). This suggests that, compared with the control group, treatment with $500 \mu \mathrm{M}$ PA for 24 hours resulted in excessive autophagy flow. The ratio of LC3II/LC3I in $500 \mu \mathrm{M}$ PAtreated cells was significantly higher than in the control cells (Figures $3(\mathrm{~d})$ and $3(\mathrm{e}), P<0.05)$, which indicates that $500 \mu \mathrm{M}$ PA increased the conversion of LC3I to LC3II. As an increase of LC3 conversion means enhanced autophagy flow [22], this supported the conclusion that $500 \mu \mathrm{M}$ PA augmented autophagy.

3.3. PA Decreased Remaining Autophagy-Related-Gene Proteins at $24 \mathrm{~h}$. In addition to the LC3 analysis, we also measured the protein expression levels of autophagy-relatedgenes (Atg) by Western blot after $24 \mathrm{~h}$ treatment. Exposure to $500 \mu \mathrm{M}$ PA with or without RAP caused a larger decrease in protein levels of Atg12-Atg5 compared to the control (Figures 4(a) and 4(d), $P<0.05)$. Also, $500 \mu \mathrm{M}$ PA + RAP group showed significantly lower level of Atg12-Atg5 compared with the RAP group (Figures 4 (a) and $4(\mathrm{~d}), P<0.05$ ). Since Atg12 combines with Atg5 soon after it is synthesized [26], we did not detect free Atg12 (data not shown). Atg16L1 binds to Atg12-Atg5 to form a homodimer, and Atg12-Atg5Atg16L1 dimers are important for LC3-PE conjugation [26]. Western data showed that $500 \mu \mathrm{M}$ PA led to significantly decreased Atg16L1 levels (Figures 4(b) and 4(e), $P<0.05$ ). 


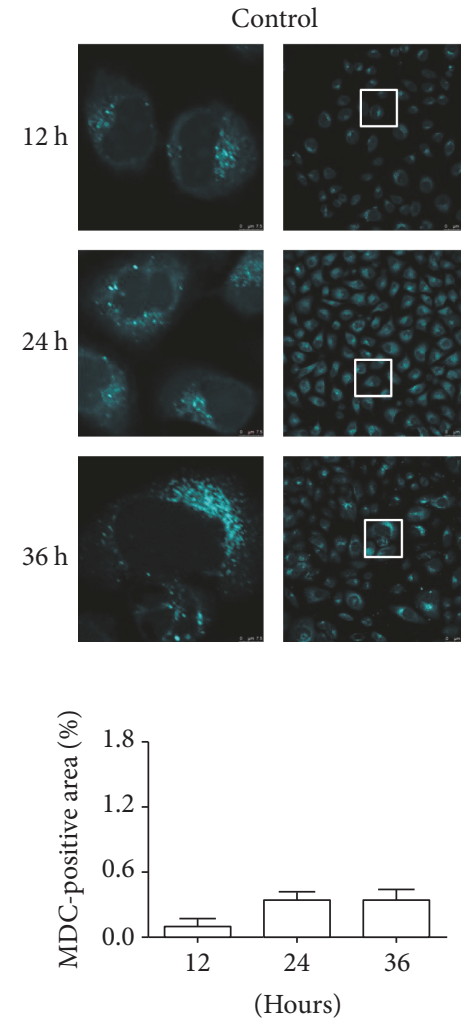

(b)

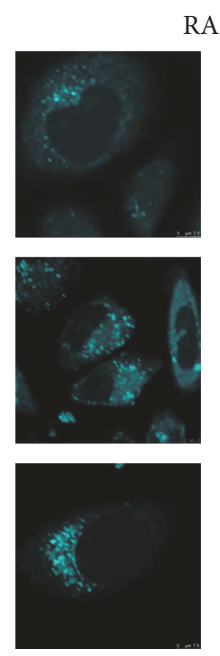

AP
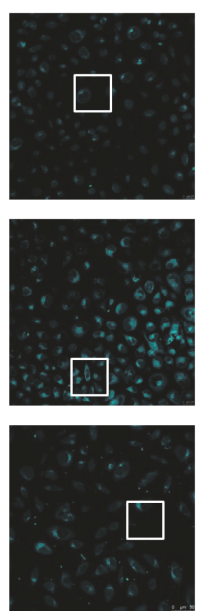

(a)

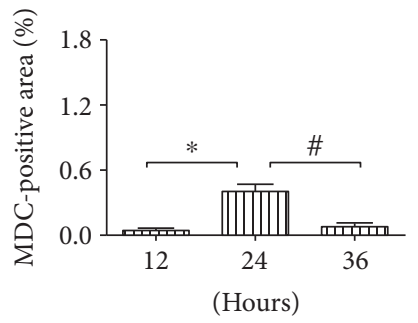

(c)
PA
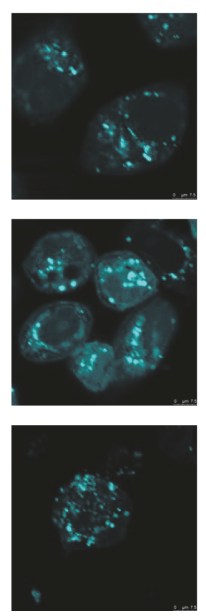

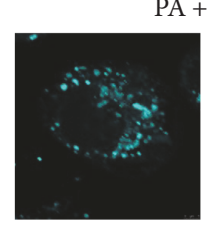

PA + RAP
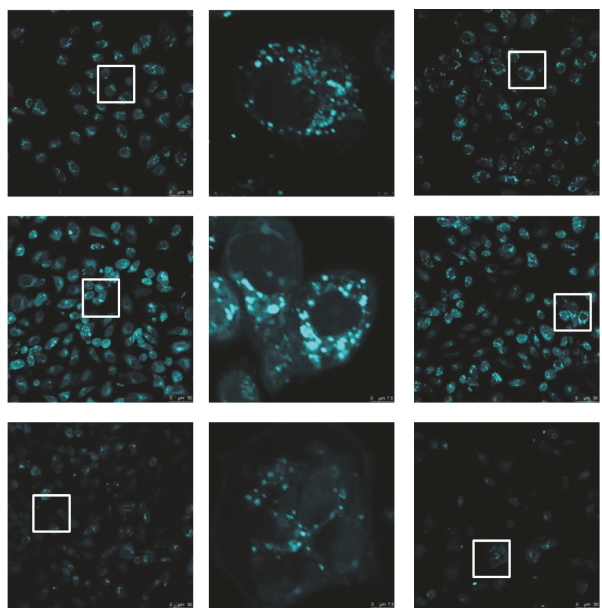

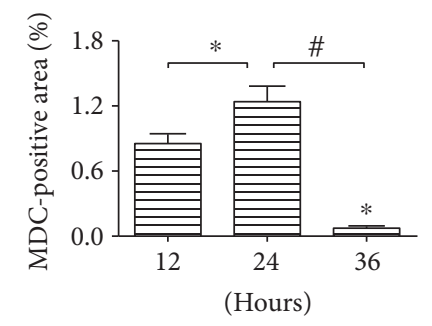

(d)

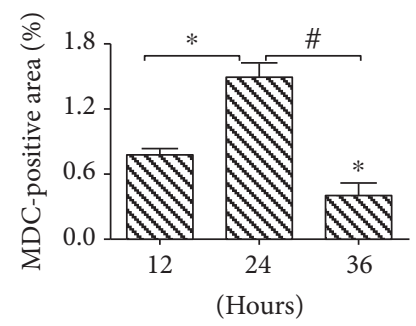

(e)

Figure 2: PA-augmented activation of autophagy flow as evidenced by MDC fluorescence. (a) H9c2 cells were treated as in Figure 1 and cultured for 12, 24, and $36 \mathrm{~h}$. Cells were stained with $50 \mu \mathrm{M}$ MDC for 30 minutes. MDC-positive area per visual field was counted in (b) for the control, (c) for RAP, (d) for PA, and (e) for PA+RAP group $(n=5)$. ${ }^{*} P<0.05$ compared with the 12 hour group. ${ }^{\#} P<0.05$ compared with the 24 hour group.

Atg3 is a protein necessary for LC3 activation [26]. The protein levels of Atg3 in the $500 \mu \mathrm{M}$ PA and $500 \mu \mathrm{M}$ PA + RAP groups were significantly lower than in the controls (Figures $4(\mathrm{c})$ and 4(f), $P<0.05$ ), which was consistent with the levels of Atg12-Atg5 and Atg16L1. These results, together with MDC and LC3 analysis, imply that the decreases of Atg proteins in the $500 \mu \mathrm{M}$ PA-treated cells are due to excessive autophagic activation.

3.4. PI3K/Akt/mTOR Pathway Was Involved in PA-Induced $I R$ and Dysregulated Autophagy. Does pathway upstream of autophagy change in the H9c2 IR model? To examine this, we measured the protein levels of the PI3Kp85 subunits and the mRNA levels for mTOR and Akt. The protein levels of the PI3Kp85 subunit in the RAP, $500 \mu \mathrm{M}$ PA, and $500 \mu \mathrm{M}$ $\mathrm{PA}+\mathrm{RAP}$ groups were lower than that in the control (Figures $4(\mathrm{~g})$ and $4(\mathrm{~h}), P<0.05)$. The mTOR mRNA in $500 \mu \mathrm{M}$ PA and $500 \mu \mathrm{M}$ PA + RAP-treated cells were higher than that in the controls (Figure 4(i), $P<0.05$ ). No significant changes in the mRNA levels of Akt were observed (data not shown).

3.5. $500 \mu M$ Palmitic Acid Reduced Viability and Increased Apoptosis of H9c2 Cells. We next explored whether PA influenced cell viability and apoptosis in the $\mathrm{H} 9 \mathrm{c} 2$ insulin resistance model. H9c2 cells were exposed to $500 \mu \mathrm{M}$ PA with or without $100 \mathrm{nM}$ RAP for 12,24 , and 36 hours, and cell viability was measured using MTS. Our results revealed that $500 \mu \mathrm{M}$ PA reduced the viability of $\mathrm{H} 9 \mathrm{c} 2$ cells compared with the control (Figures 5(a) and 5(c), $P<0.05$ ) at all of the time points, whereas, cell viability in the $250 \mu \mathrm{M}$ PA group at $24 \mathrm{~h}$ did not change (Figure 5(d), $P>0.05$ ).

To understand the mechanisms underlying PA-induced cytotoxicity of H9c2 cells, we explored the role of apoptosis after treatment of H9c2 cells with PA. An Annexin V/PI analysis was used to measure apoptosis. Our data showed that the rate of apoptosis in $500 \mu \mathrm{M}$ PA-treated cells did not change at 12 hours (Figures $5(\mathrm{e})$ and $5(\mathrm{~h}), P>0.05$ ) but was significantly increased at $24 \mathrm{~h}$ and $36 \mathrm{~h}$ compared with the control (Figures 5(f), 5(g), 5(h), 5(i), and 5(j), $P<0.05$ ). These results suggest that $500 \mu \mathrm{M}$ PA increases the level of apoptosis during the development of $\mathrm{H} 9 \mathrm{c} 2$ insulin resistance. $\mathrm{Bcl} 2$ and beclin1 are key proteins for the interactions between apoptosis and autophagy [27] As a BH3-only Bcl2 family protein, Beclin1 is regulated by $\mathrm{Bcl} 2$ family proteins through its $\mathrm{BH} 3$ domain [28]. Treatment of $\mathrm{H} 9 \mathrm{c} 2$ cells with $500 \mu \mathrm{M}$ PA for 24 hours decreased the protein levels of $\mathrm{Bcl} 2$ (Figures $5(\mathrm{k})$ and $5(\mathrm{l}), P<0.05)$ while the mRNA levels of Beclin1 mRNA were significantly higher than in the three other groups (Figure 5(m), $P<0.05$ ). 


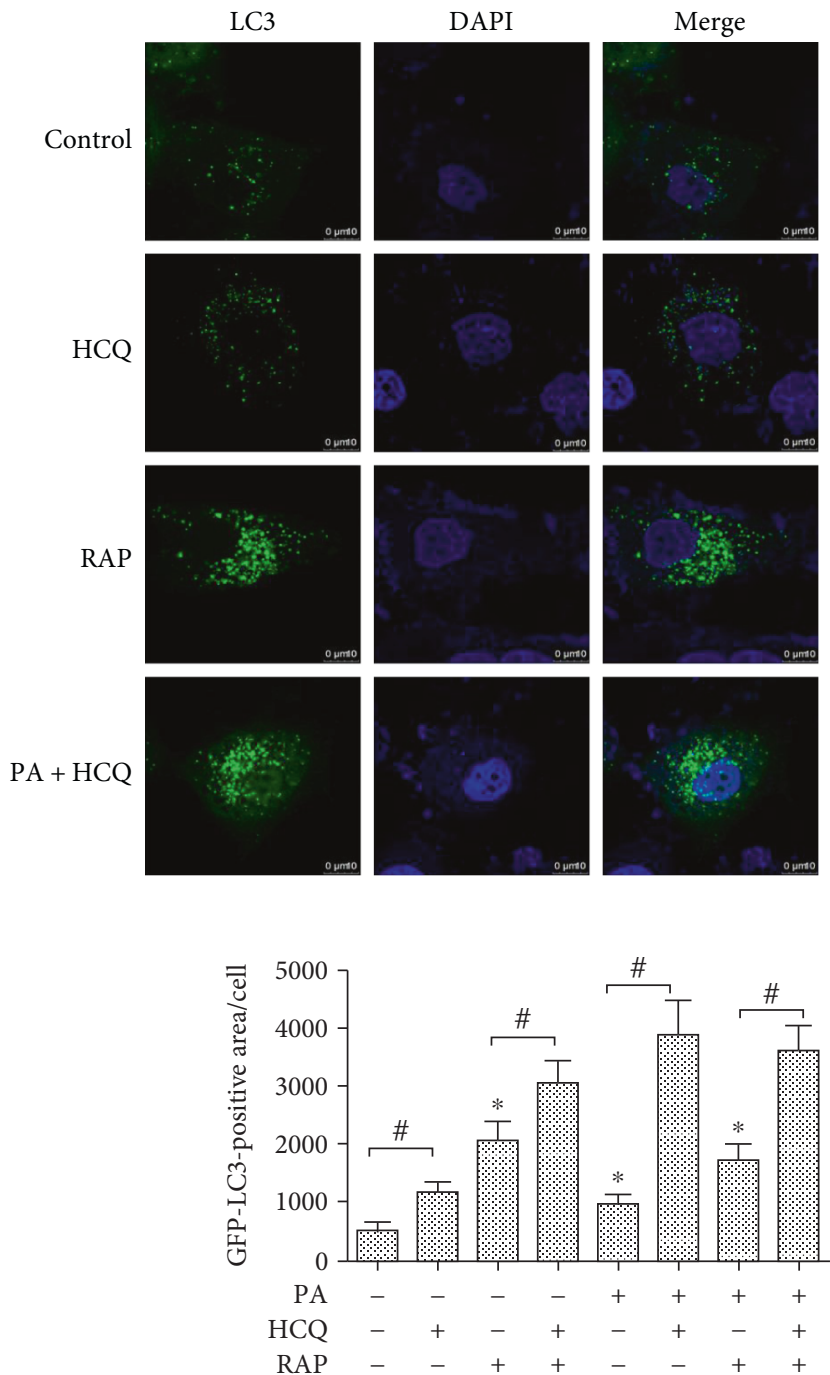

(b)

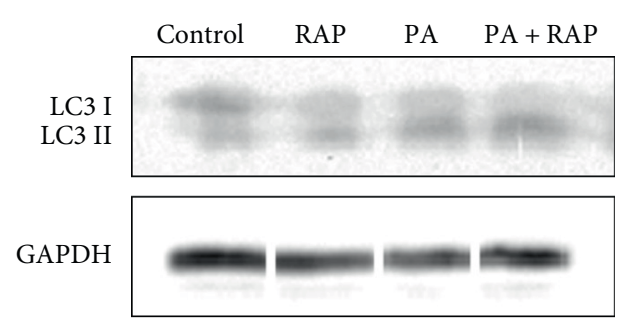

(d)

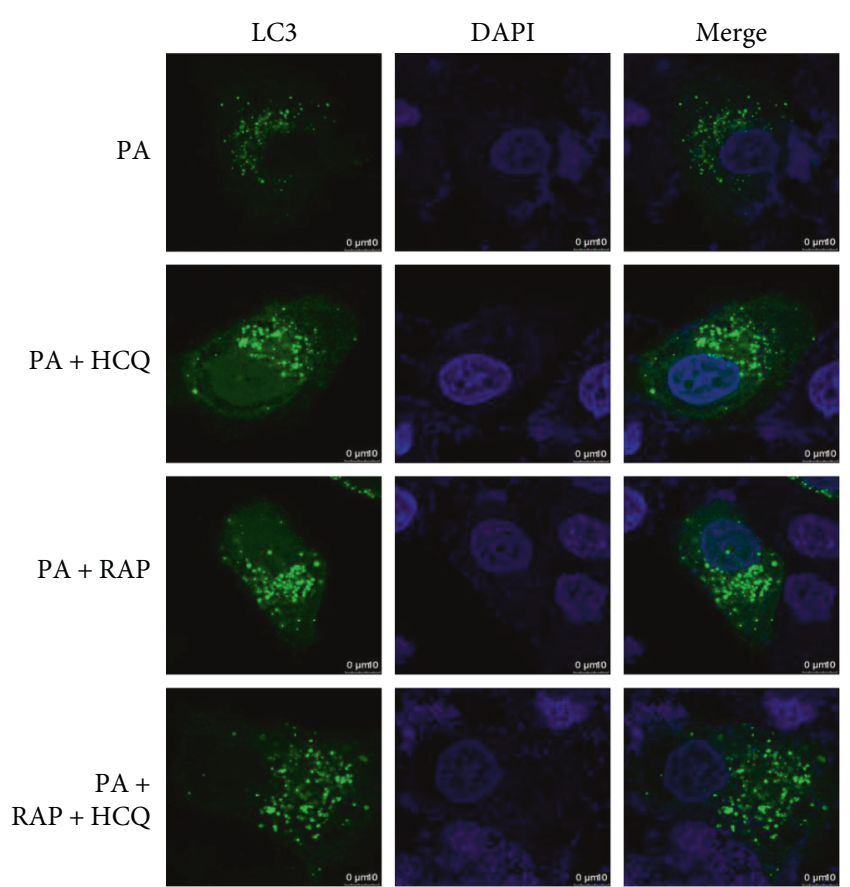

(a)

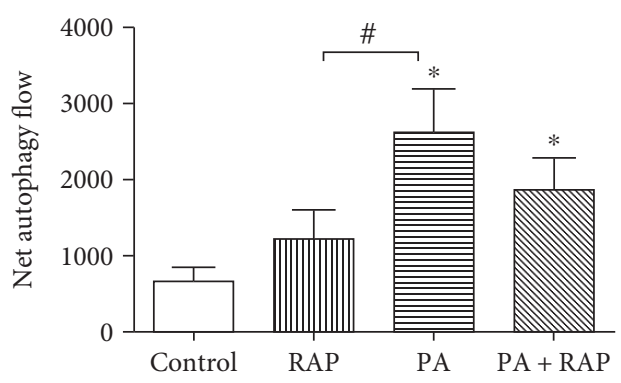

(c)

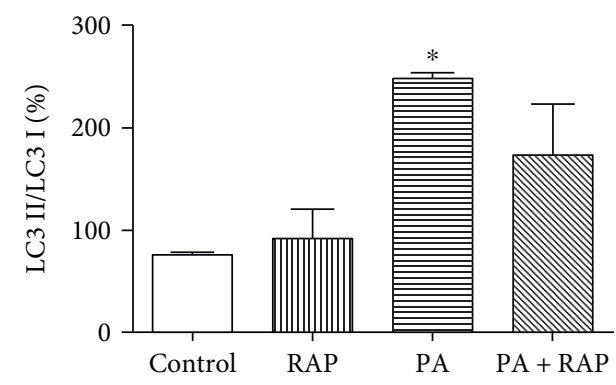

(e)

Figure 3: PA did not block autophagy, as evidenced by GFP-LC3 fluorescence and LC3 conversion. (a) H9c2 was treated with or without $500 \mu \mathrm{M}$ PA, $100 \mathrm{nM}$ RAP, and cultured for $24 \mathrm{~h}$. HCQ $(50 \mu \mathrm{M})$ was added for the last 2 hours. GFP-LC3 puncta were visualized by confocal microscopy. (b) GFP-LC3 puncta area per cell was measured from 10 random visual fields. (c) "LC3 net flux" was calculated for each of the treatments $(n=10)$. (d, e) H9c2 cells were treated as in Figure 1 for $24 \mathrm{~h}$, and LC3II/LC3I levels were semiquantitated by Western blot and compared with GAPDH $(n=3) .{ }^{*} P<0.05$ compared with the control. ${ }^{\#} P<0.05$ compared with the arrow-headed group.

\section{Discussions}

Several factors have been proposed to cause IR, including inflammation, mitochondrial dysfunction, hyperinsulinemia, hyperlipidemia, and aging [3]. Many of these factors are associated with obesity, which is the major risk factor for IR in the general population [29]. Lipotoxicity induced by high concentrations of circulating FFA is a key mechanism of IR 


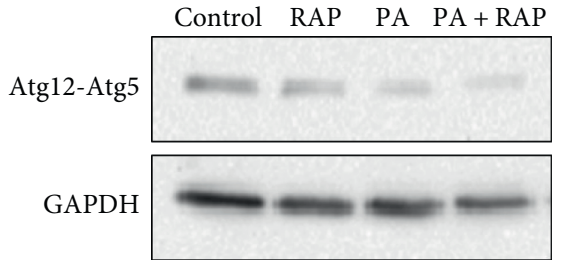

(a)

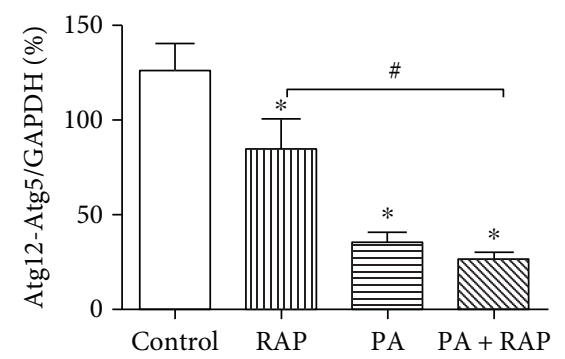

(d)

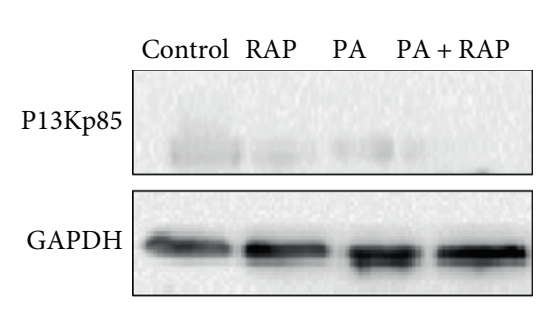

(g)

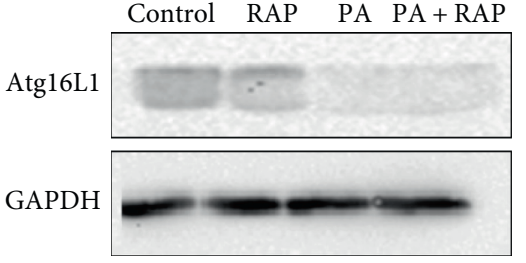

(b)

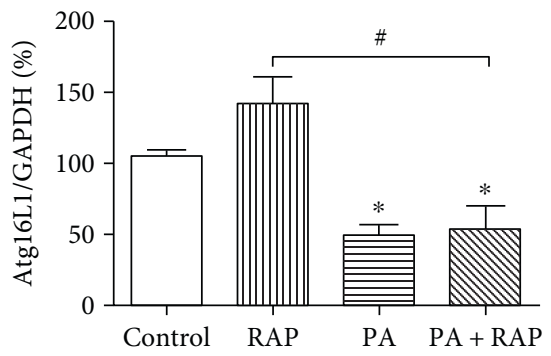

(e)

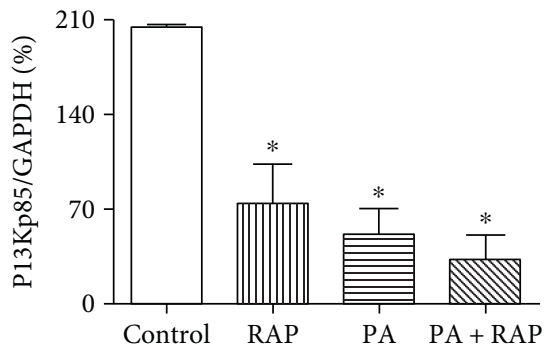

(h)

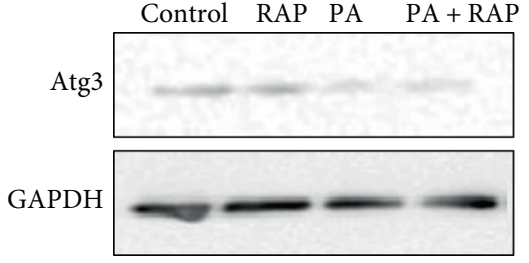

(c)

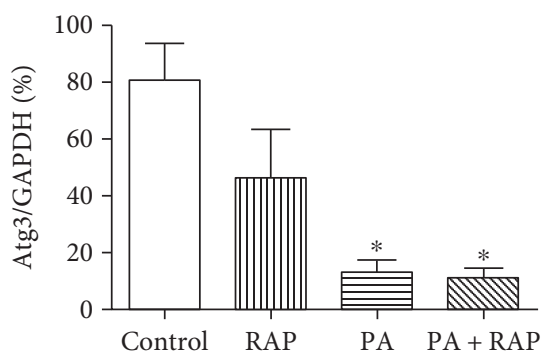

(f)

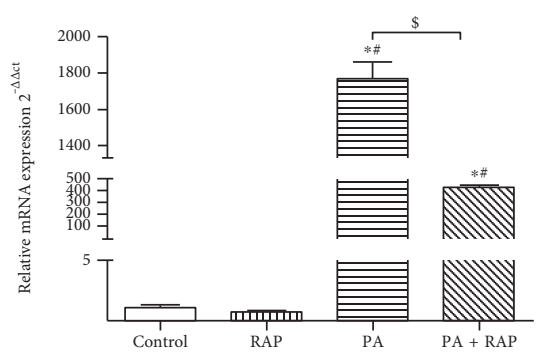

(i)

FIgure 4: Changes in Atg and PI3K proteins and mTOR mRNA after PA treatment for $24 \mathrm{~h}$. (a-h) H9c2 was treated as in Figure 1 for $24 \mathrm{~h}$. Protein levels of Atg12-Atg5, Atg16L1, Atg3, and PI3Kp85 were semiquantitated by Western blot compared with GAPDH. ( $n=3$ ). (i) H9c2 cells were treated as in Figure 1 for $24 \mathrm{~h}$, and the mRNA of levels mTOR were measured by semiquantitative RT-PCR, with $\beta$-actin as the control. $(n=3) .{ }^{*} P<0.05$ compared with the control. ${ }^{\#} P<0.05$ compared with the RAP group. ${ }^{\$} P<0.05$ compared with the PA + RAP group.

development, and among these FFAs, PA is the most common [30]. Several studies have revealed that PA influences autophagy, but their conclusions were controversial $[13,24]$. In the present study, we addressed the effects of PA on autophagy in IR cardiomyocytes.

First, we established a cardiomyocyte IR model by exposing $\mathrm{H} 9 \mathrm{c} 2$ to $500 \mu \mathrm{M}$ PA for 24 hours, as Cao et al. showed that insulin resistance effect was induced in primary rat ventricular myocytes treated with $500 \mu \mathrm{M}$ PA [10]. The cell model was validated by inhibition of glucose consumption and decreases in the protein levels for IR- $\beta$ and IRS2. IR- $\beta$ tyrosine kinase, when activated by insulin, phosphorylates IRS proteins [31]. IRS1 and IRS2 then activate the PI3K/ Akt pathway. Studies have shown that IRS2 polymorphisms are related to insulin resistance, thus IR- $\beta$ and IRS2 are useful markers for the detection of insulin resistance [32]. Our results were similar with those from previous studies. For example, murine $\mathrm{C} 2 \mathrm{C} 12$ myotubes and human umbilical vein endothelial cells (HUVECs) [33] required $750 \mu \mathrm{M}$ and $100 \mu \mathrm{M}$ PA, respectively, to induce IR. As these cells are from different species and tissues, the cellular metabolism is likely not the same; thus, differing levels of PA lead to IR. PAinduced IR is also observed in animal models. Battiprolu et al. [34] showed that mice develop myocardial IR in response to high fat-diet, where it is characterized by downregulation of IR activity, decreased Akt signaling, and a shift from glucose to fatty acid utilization. Therefore, we established a cardiomyocyte IR by saturated fatty acid.

Autophagy is a lysosomal degradation process through which misfolded proteins and organelles are sequestered, degraded by lysosomes, and recycled [15]. Autophagy is an essential part of cardiomyocyte homeostasis and increases the survival of cells following cellular stress and starvation [35]. Under conditions of nutrient deprivation, induction of autophagy provides cells with an opportunity to reutilize their own constituents for energy [22]. However, under specific circumstances, autophagy not only protects cells against death but also mediates cell death. The morphological features of autophagy, which are distinct from apoptosis, have been observed in dying cells. If autophagy destroys cytosol and organelles beyond a certain threshold, then autophagic cell death will occur [36]. As glucose uptake is impaired in tissues with insulin resistance, we investigate whether autophagy changed in response to IR in our H9c2 IR model. MDC labelling was used to detect acidic vesicles, including autophagosomes formation [21, 37]. We found that autophagy flow in $\mathrm{H} 9 \mathrm{c} 2$ cells exposed to $500 \mu \mathrm{M}$ PA rose in the first 24 hours and then declined. LC3II is considered to 


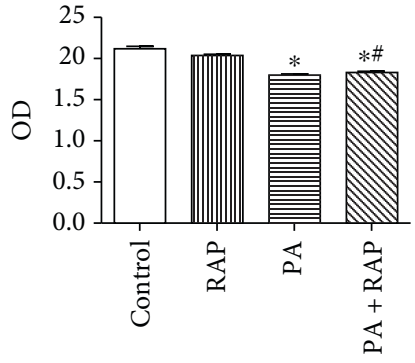

(a)

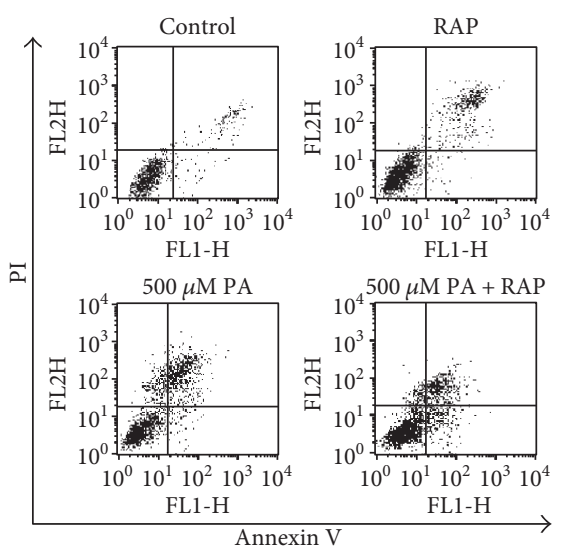

(e)

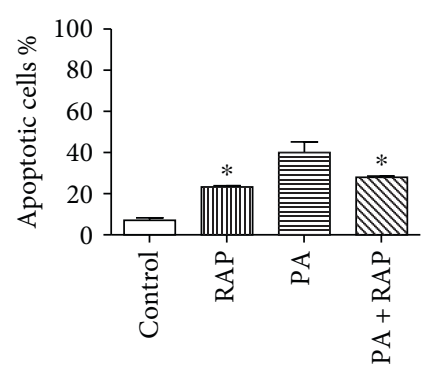

(h)

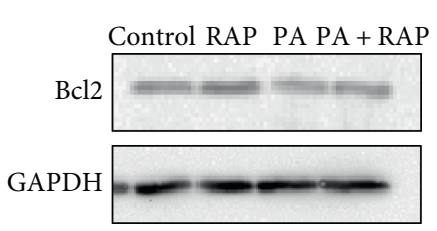

(k)

(b)
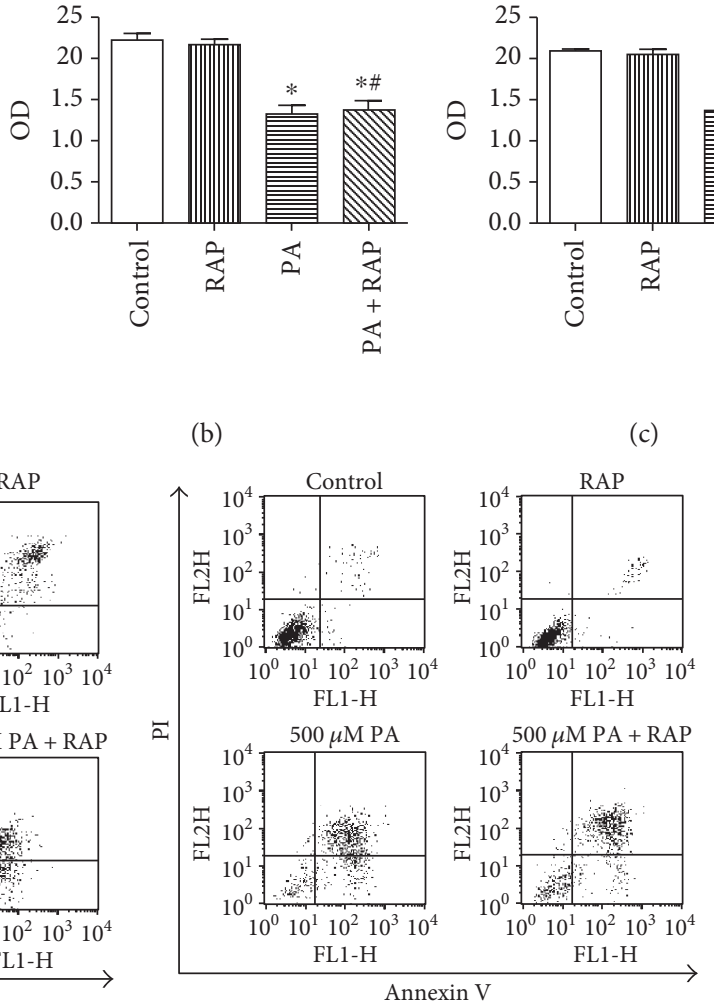

(f)

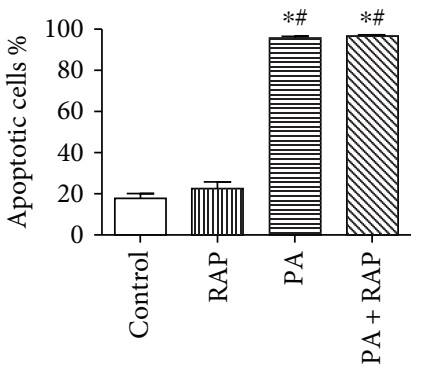

(i)

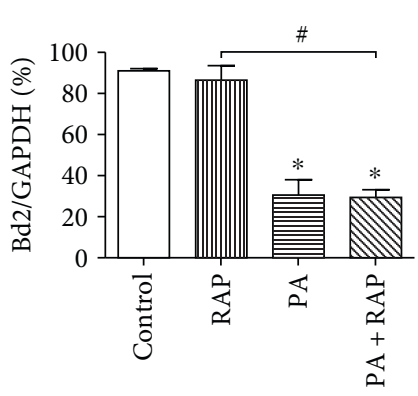

(1)
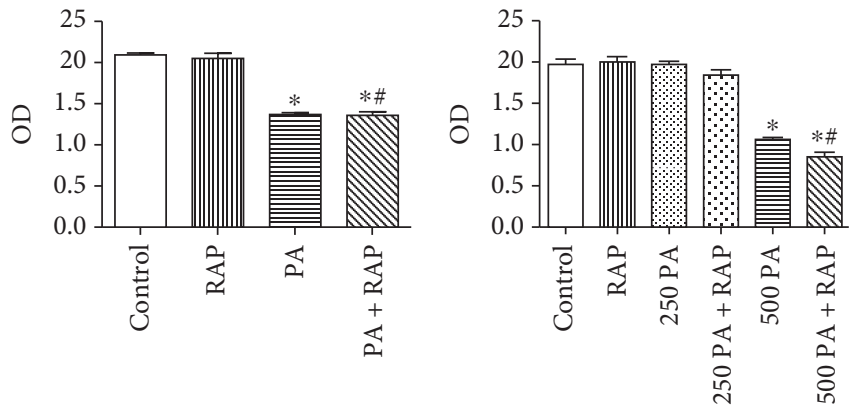

(d)

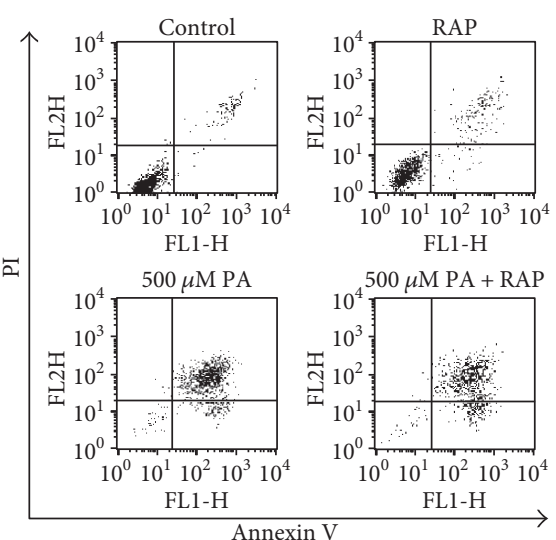

(g)

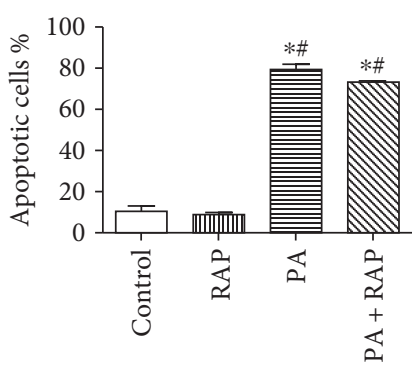

(j)

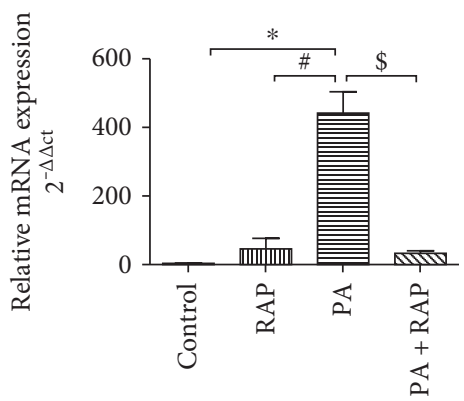

(m)

FiguRE 5: Increased apoptosis of H9c2 cells treated with $500 \mu \mathrm{M}$ PA. (a-d) H9c2 cells were treated with $250 \mu \mathrm{M}$ and $500 \mu \mathrm{M}$ PA, cultured for $24 \mathrm{~h}$, and viability was measured by the MTS assay. (e-j) Changes in the rate of apoptosis with PA treatment. H9c2 were treated as in Figure 1 and cultured for $12 \mathrm{~h}(\mathrm{e}, \mathrm{h}), 24 \mathrm{~h}(\mathrm{f}, \mathrm{i})$, and $36 \mathrm{~h}(\mathrm{~g}, \mathrm{j})$. Annexin V/PI staining flow cytometry was used to quantify the proportion of cells undergoing apoptosis. (e-g) Typical graphs for each time points. (h-j) Quantification of the flow cytometry results. Percentage of apoptotic cells is the sum of the events in the upper right and lower right quadrants. $(\mathrm{k}, \mathrm{l}) \mathrm{H} 9 \mathrm{c} 2$ were treated as in Figure 1 for $24 \mathrm{~h}$, and $\mathrm{Bcl} 2$ protein was semiquantitated by Western blot, with GAPDH as the loading control $(n=3)$. (m) mRNA levels of Beclin1 were measured by semiquantitative RT-PCR with $\beta$-actin as the control $(n=3)$. ${ }^{*} P<0.05$ compared with the control. ${ }^{\#} P<0.05$ compared with the RAP groups. ${ }^{\$} P<0.05$ compared with the PA + RAP group. 


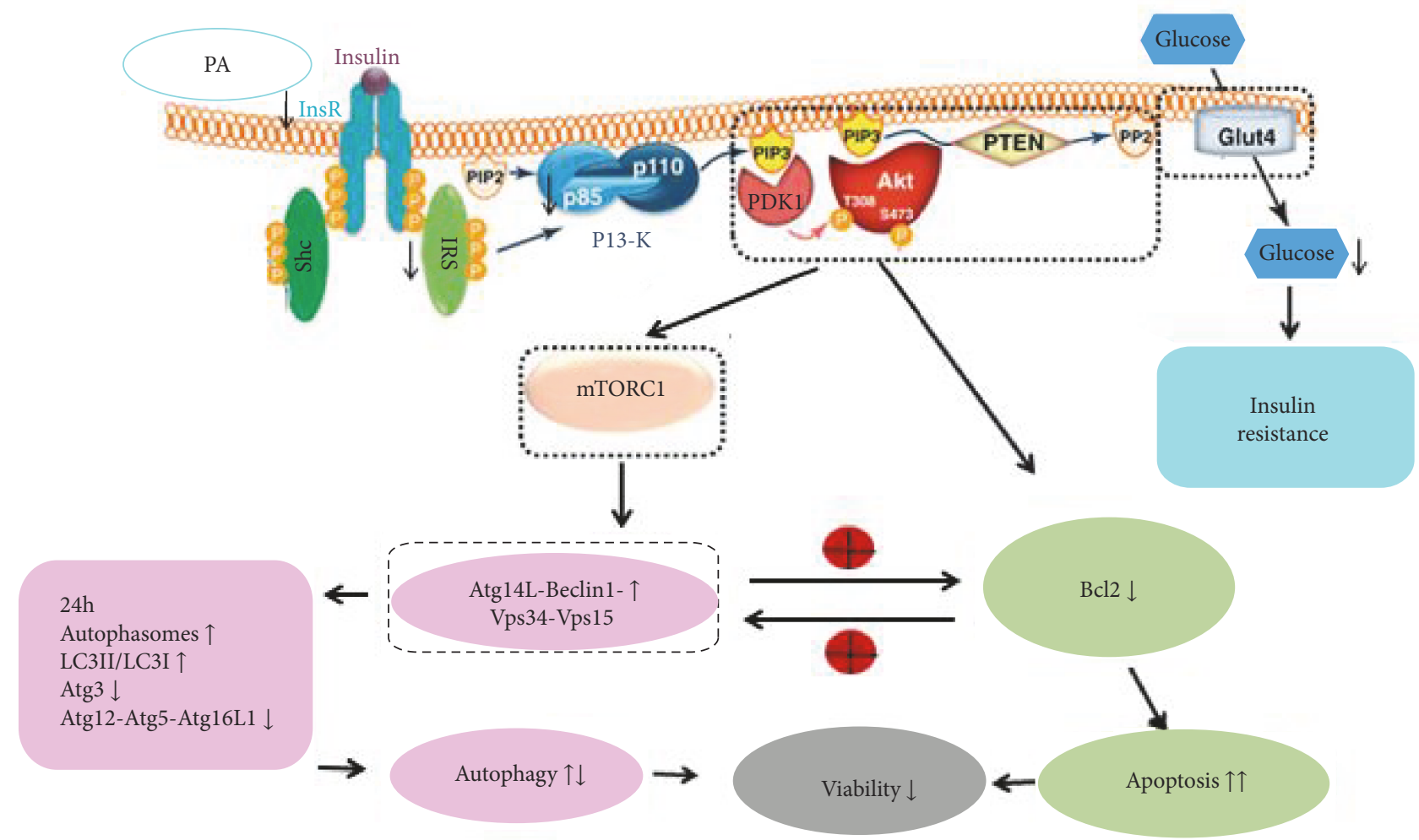

FIgURE 6: Relationship among PA-induced insulin resistance, autophagy, apoptosis, and inhibition of the PI3K/Akt/mTOR pathway. Insulin resistance was induced in $\mathrm{H} 9 \mathrm{c} 2$ cells with $500 \mu \mathrm{M}$ PA for $24 \mathrm{~h}$. During the development of IR, the numbers of autophagic acid vesicles increased during the first 24 hours and then decreased by 36 hours after PA treatment. Western blot analysis showed that the treatment of H9c2 cells with $500 \mu \mathrm{M}$ PA for 24 hours decreased the expression of Atg12-Atg5, Atg16L1, Atg3, and PI3Kp85. Annexin V/PI flow cytometry revealed that PA exposure for 24 hours increased the rate of apoptosis. The PI3K/Akt/mTOR pathway was inhibited after the PA treatment.

be an autophagosome marker in mammals, and higher LC3II/LC3I ratios indicate increased autophagy flow [26]. Experiments detecting GFP-LC3 puncta demonstrated that HCQ treatment significantly increased the accumulation of LC3II (designated as "LC3 net flux") in each treatment after $24 \mathrm{~h}$. These results demonstrate that PA activates excessive autophagy at its initial formation rather than blocking the fusion of autophagosomes with lysosomes. Excessive autophagy was also indicated by the increased LC3I to LC3II protein conversion, and the reduction in Atg protein (Atg3, Atg12-Atg5, and Atg16L1) levels in the $500 \mu \mathrm{M}$ PA groups. All of the above results led to a conclusion that $500 \mu \mathrm{M}$ PA induced excessive autophagy activation in H9c2 cells during IR development.

Phosphatidylinositol 3-kinase (PI3K)/Akt/mTOR pathway was a link between insulin resistance and autophagy. The two major insulin receptor substrates, IRS1 and IRS2, activate PI3K/Akt pathway [31], and the PI3K/Akt/mTOR pathway inhibits autophagy when it is activated [38]. It has been demonstrated that autophagy can be inhibited by activating mTOR [39]. In our study, the PI3Kp85 subunit was expressed at lower levels in the $500 \mu \mathrm{M}$ PA-treated group compared to the control cells, with the same tendency seen in the RAP group, suggesting that PI3K was inhibited by PA. The mRNA level of mTOR was increased by PA and PA+RAP, which might be due to the feedback of the protein levels for mTOR. Accumulating evidence shows that autophagy and apoptosis are executed through distinct signaling pathways, as autophagy is mainly mediated by Atg proteins [26] and apoptosis was mainly regulated by Bcl2 family protein and caspase family [40]. Yet overlapping signals are engaged in response to specific stimuli, as researchers showed that the crosstalk could be mediated by interactions between Beclin 1 and $\mathrm{Bcl} / \mathrm{Bcl}-\mathrm{xl}$ [41]. To explore the cytotoxicity of PA during the development of IR, we employed Annexin V-FITC/PI FCM to detect cell apoptosis $[42,43]$. Our results indicate that $500 \mu \mathrm{M}$ PA also promoted apoptosis after treatment for 24 hours and more, while treatment for only 12 hours did not increase the rate of apoptosis. The protein levels for $\mathrm{Bcl} 2$ decreased dramatically in the PA and PA + RAP treated cells, compared with the controls, and the mRNA level for Beclin1 was increased with PA exposure. According to Wei et al. [27], rapid phosphorylation of Bcl2 may initially occur to promote cell survival by disrupting the Bcl2-Beclin1 complex and activating autophagy. When autophagy is no longer able to keep cells alive, the phosphorylated $\mathrm{Bcl} 2$ might then serve to inactivate its antiapoptotic function. Our findings suggest that the decreasing protein levels of Bcl2 might be another factor enhancing autophagy and apoptosis. 


\section{Conclusions}

The current study showed that PA induces IR in H9c2 cells, and this process is accompanied by an excessive activation of autophagy and increases in apoptosis. PI3K/Akt/mTOR pathway is involved in this process; our conclusion scheme is illustrated in Figure 6. Our study implies that targeting the activation of autophagy may help treating insulin resistance in DCM progression.

\section{Conflicts of Interest}

The authors declare that there is no conflict of interest regarding the publication of this paper.

\section{Authors' Contributions}

Shanxin Li and Hui Li are the co-first authors. Shanxin Li and Hui Li contributed equally to this study.

\section{Acknowledgments}

This study was supported by grants from the National Natural Science Foundation of China (NSFC) Grant nos. 81102484 and 30772603, the National Key Technologies R\&D Program (Grant nos. 2006BAF07B01, 2009BAK61B01, 2009BAK61B04, and 2012BAK25B01), and a grant from the National Science Foundation of China-Canadian Institutes of Health Research (NSFC-CIHR) China-Canada Joint Health Research Initiative (Grant nos. 81061120525 and CCI-109605).

\section{References}

[1] K. Ogurtsova, J. D. da Rocha Fernandes, Y. Huang et al., "IDF diabetes atlas: global estimates for the prevalence of diabetes for 2015 and 2040," Diabetes Research and Clinical Practice, vol. 128, pp. 40-50, 2017.

[2] Z. Xu, J. Sun, Q. Tong et al., "The role of ERK1/2 in the development of diabetic cardiomyopathy," International Journal of Molecular Sciences, vol. 17, no. 12, p. 2001, 2016.

[3] I. Falcao-Pires and A. F. Leite-Moreira, "Diabetic cardiomyopathy: understanding the molecular and cellular basis to progress in diagnosis and treatment," Heart Failure Reviews, vol. 17, no. 3, pp. 325-344, 2012.

[4] R. Reynoso, L. M. Salgado, and V. Calderon, "High levels of palmitic acid lead to insulin resistance due to changes in the level of phosphorylation of the insulin receptor and insulin receptor substrate-1," Molecular and Cellular Biochemistry, vol. 246, no. 1-2, pp. 155-162, 2003.

[5] A. Fragoso, F. Mendes, A. P. Silva, and P. L. Neves, "Insulin resistance as a predictor of cardiovascular morbidity and end-stage renal disease," Journal of Diabetes and its Complications, vol. 29, no. 8, pp. 1098-1104, 2015.

[6] C. Bang, C. Antoniades, A. S. Antonopoulos et al., "Intercellular communication lessons in heart failure," European Journal of Heart Failure, vol. 17, no. 11, pp. 1091-1103, 2015.

[7] L. Yuzefovych, G. Wilson, and L. Rachek, "Different effects of oleate vs. palmitate on mitochondrial function, apoptosis, and insulin signaling in L6 skeletal muscle cells: role of oxidative stress," American Journal of Physiology Endocrinology and Metabolism, vol. 299, no. 6, pp. E1096-E1105, 2010.

[8] W. Zhao, C. Wu, S. Li, and X. Chen, "Adiponectin protects palmitic acid induced endothelial inflammation and insulin resistance via regulating ROS/IKK $\beta$ pathways," Cytokine, vol. 88, pp. 167-176, 2016.

[9] J. Gustavo Vazquez-Jimenez, J. Chavez-Reyes, T. RomeroGarcia et al., "Palmitic acid but not palmitoleic acid induces insulin resistance in a human endothelial cell line by decreasing SERCA pump expression," Cellular Signalling, vol. 28, no. 1, pp. 53-59, 2016.

[10] C. Cao, Y. Chen, W. Wang, Y. Liu, and G. Liu, "Ghrelin inhibits insulin resistance induced by glucotoxicity and lipotoxicity in cardiomyocyte," Peptides, vol. 32, no. 2, pp. 209-215, 2011.

[11] N. Mizushima and M. Komatsu, "Autophagy: renovation of cells and tissues,” Cell, vol. 147, no. 4, pp. 728-741, 2011.

[12] L. Yang, P. Li, S. Fu, E. S. Calay, and G. S. Hotamisligil, "Defective hepatic autophagy in obesity promotes ER stress and causes insulin resistance," Cell Metabolism, vol. 11, no. 6, pp. $467-478,2010$.

[13] A. Ost, K. Svensson, I. Ruishalme et al., "Attenuated mTOR signaling and enhanced autophagy in adipocytes from obese patients with type 2 diabetes," Molecular Medicine, vol. 16, no. 7-8, pp. 235-246, 2010.

[14] D. J. Klionsky, K. Abdelmohsen, A. Abe et al., "Guidelines for the use and interpretation of assays for monitoring autophagy (3rd edition)," Autophagy, vol. 12, no. 1, pp. 1-222, 2016.

[15] Q. Wang, T. You, H. Fan et al., "Rapamycin and bafilomycin A1 alter autophagy and megakaryopoiesis," Platelets, vol. 28, no. 1, pp. 82-89, 2017.

[16] J. Yin, L. Gu, Y. Wang, N. Fan, Y. Ma, and Y. Peng, "Rapamycin improves palmitate-induced ER stress $/ \mathrm{NF} \kappa \mathrm{B}$ pathways associated with stimulating autophagy in adipocytes," Mediators of Inflammation, vol. 2015, Article ID 272313, 12 pages, 2015.

[17] W. Chang, M. Zhang, J. Li et al., "Berberine improves insulin resistance in cardiomyocytes via activation of $5^{\prime}$-adenosine monophosphate-activated protein kinase," Metabolism: Clinical and Experimental, vol. 62, no. 8, pp. 1159-1167, 2013.

[18] J. A. Chavez, T. A. Knotts, L. P. Wang et al., “A role for ceramide, but not diacylglycerol, in the antagonism of insulin signal transduction by saturated fatty acids," The Journal of Biological Chemistry, vol. 278, no. 12, pp. 10297-10303, 2003.

[19] Y. Chen, Y. Li, Y. Wang, Y. Wen, and C. Sun, "Berberine improves free-fatty-acid-induced insulin resistance in L6 myotubes through inhibiting peroxisome proliferator-activated receptor $\gamma$ and fatty acid transferase expressions," Metabolism: Clinical and Experimental, vol. 58, no. 12, pp. 1694-1702, 2009.

[20] C. Corral-Ramos, M. G. Roca, A. Di Pietro, M. I. Roncero, and C. Ruiz-Roldán, "Autophagy contributes to regulation of nuclear dynamics during vegetative growth and hyphal fusion in Fusarium oxysporum," Autophagy, vol. 11, no. 1, pp. 131144, 2015.

[21] A. Kim, M. Im, N. H. Yim, T. Kim, and J. Y. Ma, "A novel herbal medicine, KIOM-C, induces autophagic and apoptotic cell death mediated by activation of JNK and reactive oxygen species in HT1080 human fibrosarcoma cells," PLoS One, vol. 9, no. 5, article e98703, 2014. 
[22] Y. M. Song, Y. H. Lee, J. W. Kim et al., "Metformin alleviates hepatosteatosis by restoring SIRT1-mediated autophagy induction via an AMP-activated protein kinase-independent pathway," Autophagy, vol. 11, no. 1, pp. 46-59, 2015.

[23] K. J. Livak and T. D. Schmittgen, "Analysis of relative gene expression data using real-time quantitative PCR and the $2^{-\Delta \Delta C T}$ method," Methods, vol. 25, no. 4, pp. 402-408, 2001.

[24] M. Portovedo, L. M. Ignacio-Souza, B. Bombassaro et al., "Saturated fatty acids modulate autophagy's proteins in the hypothalamus," PLoS One, vol. 10, no. 3, article e0119850, 2015.

[25] Y. Haim, M. Bluher, N. Slutsky et al., "Elevated autophagy gene expression in adipose tissue of obese humans: a potential noncell-cycle-dependent function of E2F1," Autophagy, vol. 11, no. 11, pp. 2074-2088, 2015.

[26] N. Mizushima, T. Yoshimori, and Y. Ohsumi, "The role of Atg proteins in autophagosome formation," Annual Review of Cell and Developmental Biology, vol. 27, pp. 107-132, 2011.

[27] Y. Wei, S. Sinha, and B. Levine, "Dual role of JNK1-mediated phosphorylation of Bcl-2 in autophagy and apoptosis regulation," Autophagy, vol. 4, no. 7, pp. 949-951, 2008.

[28] E. Zalckvar, H. Berissi, L. Mizrachy et al., "DAP-kinase-mediated phosphorylation on the $\mathrm{BH} 3$ domain of beclin 1 promotes dissociation of beclin 1 from $\mathrm{Bcl}-\mathrm{X}_{\mathrm{L}}$ and induction of autophagy," EMBO Reports, vol. 10, no. 3, pp. 285-292, 2009.

[29] J. Ye, "Mechanisms of insulin resistance in obesity," Frontiers of Medicine, vol. 7, no. 1, pp. 14-24, 2013.

[30] E. J. Park, A. Y. Lee, S. Park, J. H. Kim, and M. H. Cho, "Multiple pathways are involved in palmitic acid-induced toxicity," Food and Chemical Toxicology, vol. 67, pp. 26-34, 2014.

[31] T. Kadowaki, K. Ueki, T. Yamauchi, and N. Kubota, "SnapShot: insulin signaling pathways," Cell, vol. 148, no. 3, p. 624.e1, 2012.

[32] P. Perez-Martinez, J. Delgado-Lista, A. Garcia-Rios et al., "Insulin receptor substrate-2 gene variants in subjects with metabolic syndrome: association with plasma monounsaturated and n-3 polyunsaturated fatty acid levels and insulin resistance," Molecular Nutrition \& Food Research, vol. 56, no. 2, pp. 309-315, 2012.

[33] K. Batumalaie, M. A. Amin, D. D. Murugan, M. Z. Sattar, and N. A. Abdullah, "Withaferin a protects against palmitic acidinduced endothelial insulin resistance and dysfunction through suppression of oxidative stress and inflammation," Scientific Reports, vol. 6, article 27236, 2016.

[34] P. K. Battiprolu, B. Hojayev, N. Jiang et al., "Metabolic stressinduced activation of FoxO1 triggers diabetic cardiomyopathy in mice," The Journal of Clinical Investigation, vol. 122, no. 3, pp. 1109-1118, 2012.

[35] M. Hashemzaei, R. Entezari Heravi, R. Rezaee, A. Roohbakhsh, and G. Karimi, "Regulation of autophagy by some natural products as a potential therapeutic strategy for cardiovascular disorders," European Journal of Pharmacology, vol. 802, pp. 44-51, 2017.

[36] K. Nishida, O. Yamaguchi, and K. Otsu, "Crosstalk between autophagy and apoptosis in heart disease," Circulation Research, vol. 103, no. 4, pp. 343-351, 2008.

[37] B. Liang, D. Kong, Y. Liu et al., “Autophagy inhibition plays the synergetic killing roles with radiation in the multi-drug resistant SKVCR ovarian cancer cells," Radiation Oncology, vol. 7, p. 213, 2012.
[38] S. W. Lee, Y. S. Song, S. Y. Lee et al., "Downregulation of protein kinase CK2 activity facilitates tumor necrosis factor$\alpha$-mediated chondrocyte death through apoptosis and autophagy," PLoS One, vol. 6, no. 4, article e19163, 2011.

[39] A. S. Chagin, "Effectors of mTOR-autophagy pathway: targeting cancer, affecting the skeleton," Current Opinion in Pharmacology, vol. 28, pp. 1-7, 2016.

[40] M. S. Ola, M. Nawaz, and H. Ahsan, "Role of Bcl-2 family proteins and caspases in the regulation of apoptosis," Molecular and Cellular Biochemistry, vol. 351, no. 1-2, pp. 41-58, 2011.

[41] L. A. Booth, S. Tavallai, H. A. Hamed, N. Cruickshanks, and P. Dent, "The role of cell signalling in the crosstalk between autophagy and apoptosis," Cellular Signalling, vol. 26, no. 3, pp. 549-555, 2014.

[42] T. Olszowski, I. Baranowska-Bosiacka, I. Gutowska et al., "The effects of cadmium at low environmental concentrations on THP-1 macrophage apoptosis," International Journal of Molecular Sciences, vol. 16, no. 9, pp. 21410-21427, 2015.

[43] N. Zhou, Y. Zhang, X. Zhang et al., "Exposure of tumorassociated macrophages to apoptotic MCF-7 cells promotes breast cancer growth and metastasis," International Journal of Molecular Sciences, vol. 16, no. 6, pp. 11966-11982, 2015. 


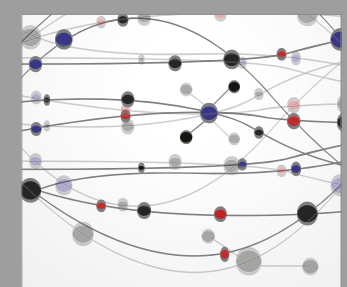

The Scientific World Journal
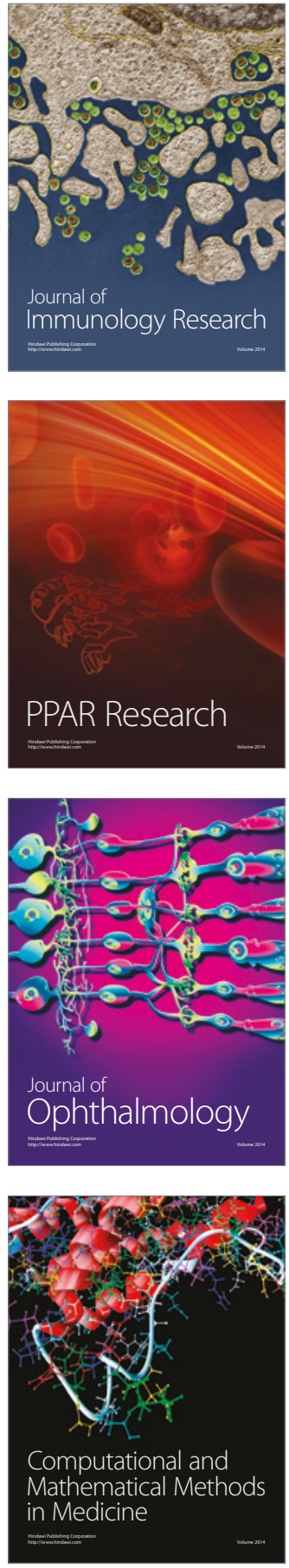

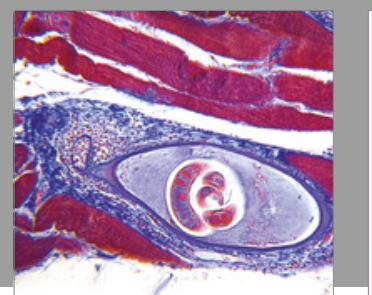

Gastroenterology Research and Practice
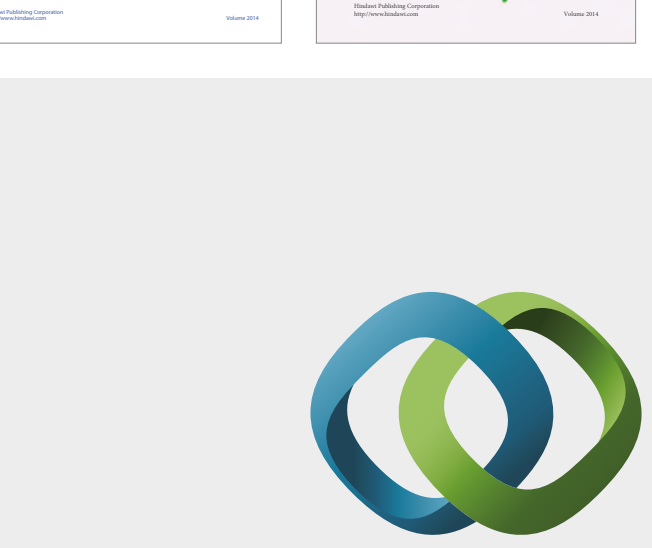

\section{Hindawi}

Submit your manuscripts at

https://www.hindawi.com
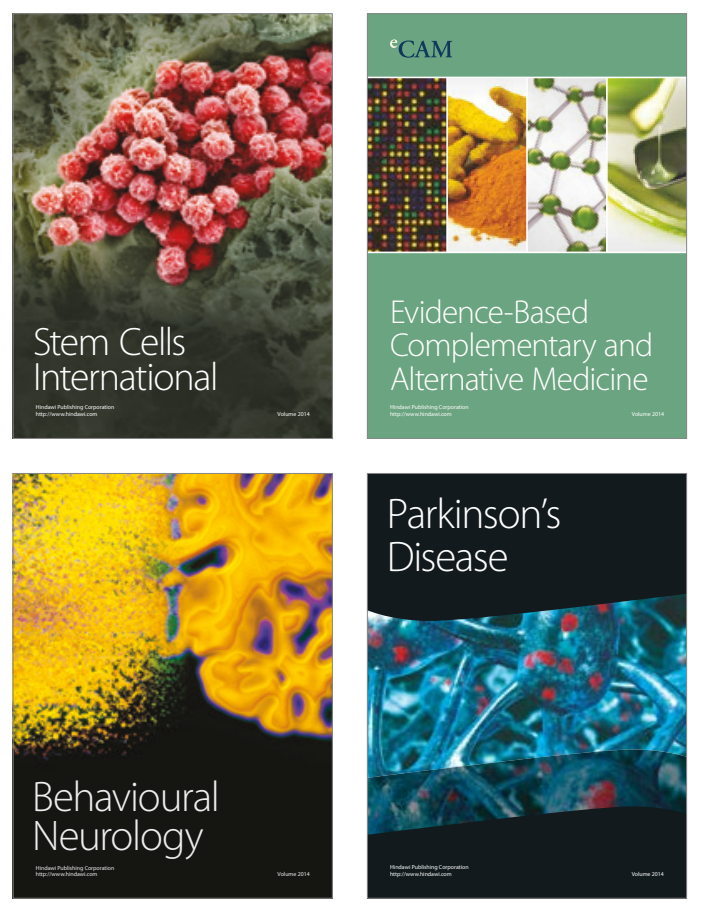
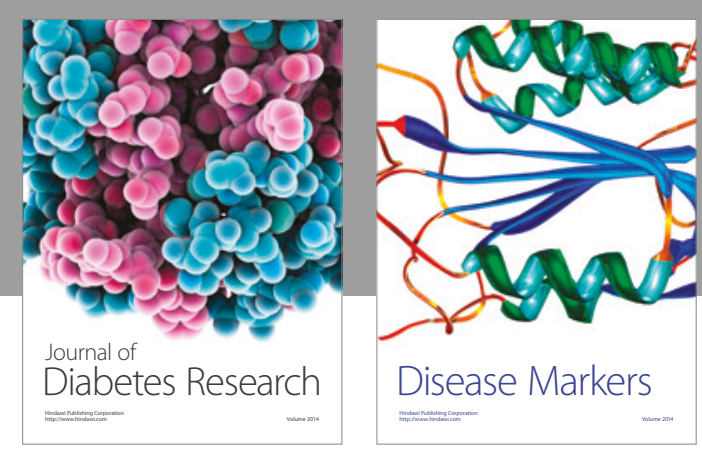

Disease Markers
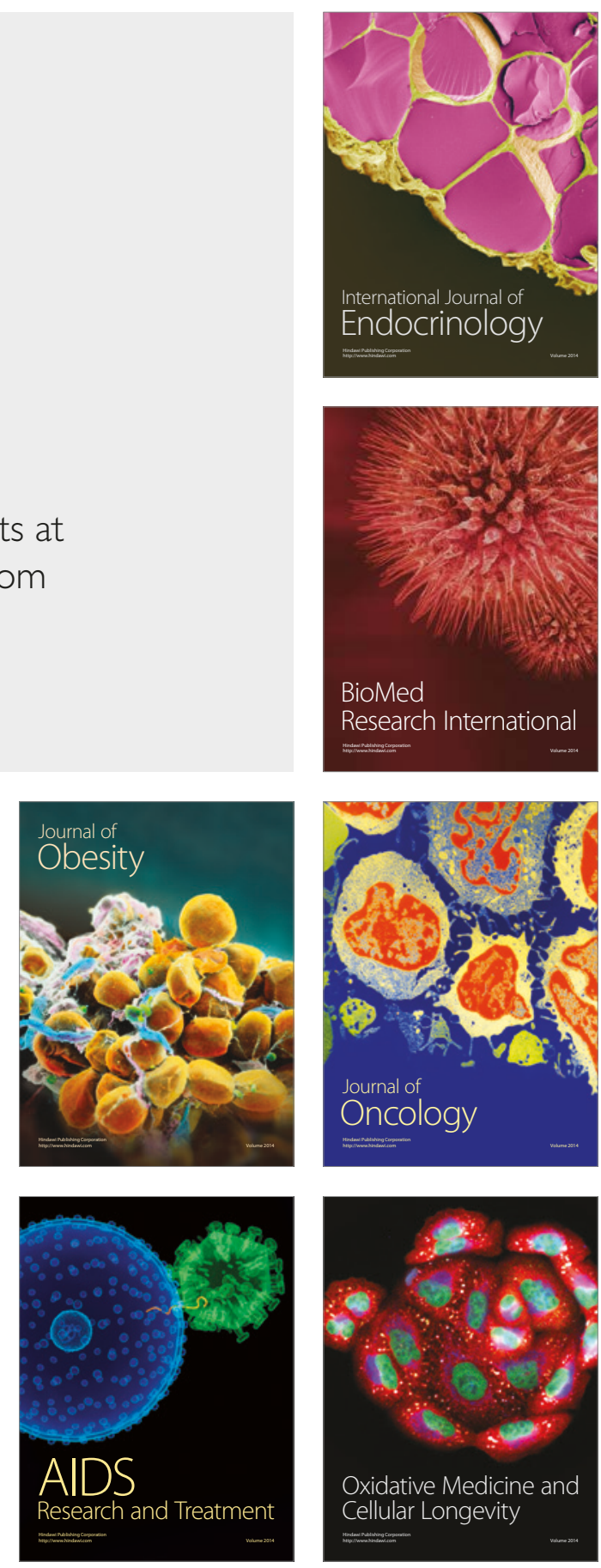